\title{
Article \\ A Versatile Strategy for the Fabrication of Poly(ethyl methacrylate) Composites
}

\author{
Kayla Baker and Igor Zhitomirsky *(D)
}

check for updates

Citation: Baker, K.; Zhitomirsky, I. A Versatile Strategy for the Fabrication of Poly(ethyl methacrylate)

Composites. J. Compos. Sci. 2022, 6,

40. https://doi.org/10.3390/

jcs6020040

Academic Editor:

Francesco Tornabene

Received: 10 December 2021

Accepted: 21 January 2022

Published: 24 January 2022

Publisher's Note: MDPI stays neutral with regard to jurisdictional claims in published maps and institutional affiliations.

Copyright: (C) 2022 by the authors. Licensee MDPI, Basel, Switzerland. This article is an open access article distributed under the terms and conditions of the Creative Commons Attribution (CC BY) license (https:// creativecommons.org/licenses/by/ $4.0 /)$.

\author{
Department of Materials Science and Engineering, McMaster University, Hamilton, ON L8S 4L7, Canada; \\ bakerk9@mcmaster.ca \\ * Correspondence: zhitom@mcmaster.ca
}

\begin{abstract}
Poly(ethyl methacrylate) (PEMA) is dissolved in ethanol, known to be a non-solvent for PEMA, due to the solubilizing ability of an added bile acid biosurfactant, lithocholic acid (LA). The ability to avoid traditional toxic and carcinogenic solvents is important for the fabrication of composites for biomedical applications. The formation of concentrated solutions of high molecular weight PEMA is a key factor for the film deposition using the dip coating method. PEMA films provide corrosion protection for stainless steel. Composite films are prepared, containing bioceramics, such as hydroxyapatite and silica, for biomedical applications. LA facilitates dispersion of hydroxyapatite and silica in suspensions for film deposition. Ibuprofen and tetracycline are used as model drugs for the fabrication of composite films. PEMA-nanocellulose films are successfully prepared using the dip coating method. The microstructure and composition of the films are investigated. The conceptually new approach developed in this investigation represents a versatile strategy for the fabrication of composites for biomedical and other applications, using natural biosurfactants as solubilizing and dispersing agents.
\end{abstract}

Keywords: composite; poly(ethyl methacrylate); film; hydroxyapatite; silica; drug; nanocellulose

\section{Introduction}

This investigation was motivated by the advanced functional properties of poly(ethylmethacrylate) polymer (PEMA), which makes it the material of choice for the fabrication of advanced composites. Of particular importance for composite development are the biocompatibility, high chemical stability, flexibility, advanced mechanical properties, and thermal stability of this polymer [1,2]. PEMA is a low-cost polymer, which has generated significant interest for its corrosion protection of metals [3], packaging [4,5], energy storage in capacitors [6] and batteries [7,8], thermal energy storage [9], and other applications. Significant enhancement of its properties and functionality was achieved by combining PEMA with other functional materials and fabrication of composites [8-10].

PEMA composites are especially promising for various biomedical applications [11]. Investigations focused on the development of PEMA composite biocements with enhanced mechanical properties and biocompatibility [11,12], shape memory composites for biomedical devices [13], composites for bone repair [14,15], and other applications in tissue engineering $[14,16]$. PEMA has promising properties for dental and orthopedic applications, craniofacial implants, and biosensors. However, PEMA is soluble only in highly carcinogenic and toxic solvents, such as benzene, toluene, and methyl ethyl ketone. This limits PEMA applications in various fields of bioengineering. The ability to use non-toxic solvents for dissolution of PEMA and fabrication of composites by colloidal techniques can provide an avenue for many advanced biomedical applications. Various bioactive ceramics such as hydroxyapatite, and silica are promising inorganic materials for the fabrication of organic-inorganic biocomposites [17-19]. There is a growing interest in the application of nanocellulose for the development of advanced biocomposites [20,21]. The 
interest in various biomedical applications of nanocellulose is related to the biocompatibility and advanced mechanical properties of this material [22,23]. Polymer-nanocellulose composites have many applications for food packaging [24], barrier coatings [25], and supercapacitors [26]. Moreover, nanocellulose is under investigation for various optical applications [27], protective barrier coatings [28], electrochromic thin film devices [29], and solar cells [30]. Various drug materials were incorporated in polymer composites [31]. The need for composite films in various biomedical applications was a motivating factor for the development of new film deposition techniques [31,32].

The goal of this investigation was to fabricate PEMA and composite films using ethanol as a solvent. We found that PEMA can be dissolved in ethanol in the presence of lithocholic acid as a natural dispersant. This process mimics the solubilization of different biomolecules in a human body in the presence of bile salts, such as lithocholic acid sodium salt. However, in contrast to the aqueous processes in the human body, we demonstrated the solubilization power of water-insoluble lithocholic acid in ethanol. An important finding was the solubilization of high molecular mass PEMA in ethanol and the ability to form concentrated solutions, which facilitated film deposition by a simple dip-coating method. The experimental results presented below indicated that PEMA films provided corrosion protection for stainless steel. Following the goal of this investigation, we fabricated PEMA based composites, containing hydroxyapatite, silica, nanocellulose and drugs. We analysed the microstructure, and composition of obtained films. The approach developed in this investigation opens a new avenue for the development of biocomposite films by colloidal techniques using non-toxic solvents.

\section{Materials and Methods}

PEMA $\left(M_{\mathrm{W}}=515,000\right)$, ibuprofen, tetracycline and lithocholic acid (LA) were purchased from Millipore (Sigma, Oakville, ON, Canada). Hydroxyapatite nanorods (150 nm length, $20 \mathrm{~nm}$ diameter) were prepared by the method developed in previous investigations [19,33]. Silica $(0.5 \mu \mathrm{m}$ size) was purchased from PCR Incorporated, (Arcade, NY, USA). Cellulose nanocrystals (CNC) were purchased from CelluForce Inc., (Montreal, QC, Canada).

LA was dissolved in ethanol at a concentration of $1 \mathrm{gL}^{-1}$. PEMA was added at a concentration of $10 \mathrm{gL}^{-1}$ to the LA solution and also to pure ethanol without LA. Upon heating to just $35^{\circ} \mathrm{C}$ the PEMA suspension containing LA turned from an opaque cloudy white to a clear and transparent solution, whereas the PEMA suspension without LA did not turn clear until heating to $55^{\circ} \mathrm{C}$. This indicated the successful dissolution of PEMA in ethanol facilitated by the small addition of the naturally occurring bile acid. After cooling to room temperature while being continuously stirred, the PEMA solutions containing LA remained stable and the PEMA solutions without LA showed precipitation of PEMA (Figure 1).

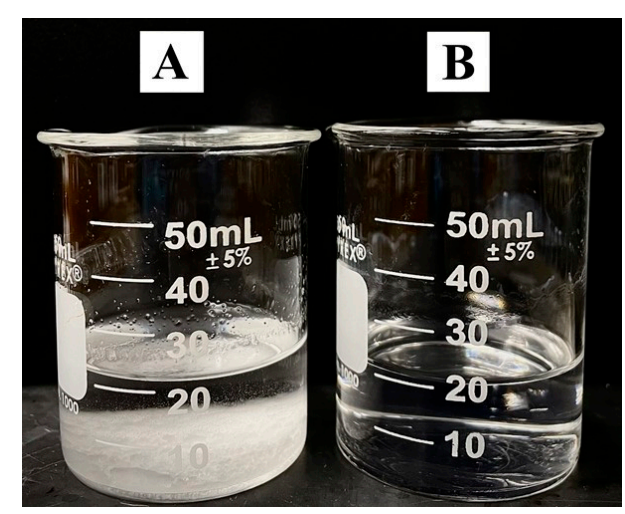

Figure 1. Effect of the presence of LA on the dissolution of PEMA shown by $10 \mathrm{gL}^{-1}$ PEMA in (A) ethanol, (B) ethanol with $1 \mathrm{gL}^{-1} \mathrm{LA}$. 
Substrates of 304 stainless steel $(0.1 \mathrm{~mm}$ thick, $2.5 \mathrm{~cm} \times 5.0 \mathrm{~cm})$ were coated using the dip coating method from $10 \mathrm{gL}^{-1}$ PEMA solutions in ethanol with $1 \mathrm{gL}^{-1} \mathrm{LA}$. The samples for electrochemical studies were annealed at $180^{\circ} \mathrm{C}$ for one hour. Composite PEMA coatings were subsequently created using the same procedure with the LA concentration being increased to $3 \mathrm{gL}^{-1}$ to help in its function as both a solubilizing agent for PEMA and a dispersing agent for other components. Bioceramics hydroxyapatite and silica were successfully dispersed at concentrations of 3-10 $\mathrm{gL}^{-1}$.

Composite coatings were also prepared containing drugs, such as tetracycline and ibuprofen, as well as with the biologically functional material nanocellulose crystals. Concentrations of tetracycline, ibuprofen, and nanocellulose were in the range of $3-10 \mathrm{gL}^{-1}$ in the $10 \mathrm{gL}^{-1}$ PEMA solution in ethanol containing $3 \mathrm{gL}^{-1} \mathrm{LA}$.

Fourier Transform Infrared Spectroscopy (FTIR) studies were performed using a Bruker Vertex 70 spectrometer. A Bruker Smart $6000 \mathrm{X}$-ray diffractometer (CuK $\alpha$ radiation) was used for X-ray diffraction analysis. All fabricated coatings were characterized by scanning electron microscopy (SEM, JOEL 7000F, Tokyo, Japan). Electrochemical testing was performed by a PARSTAT 2273 potentiostat in a 3\% NaCl solution using a 3-electrode cell composed of the coated or uncoated stainless-steel substrate as the working electrode, a saturated calomel electrode (SCE) as the reference electrode, and a Pt counter electrode. Potentiodynamic polarization tests were performed at a scan rate of $1 \mathrm{mVs}^{-1}$. The deposits were removed from the stainless-steel substrate for thermogravimetric analysis (TGA), which was performed using a thermoanalyzer (Netzsch STA-409, Exton, PA, USA), operated in air at a heating rate of $10{ }^{\circ} \mathrm{C} \mathrm{min}-1$.

\section{Results and Discussion}

The successful application of the dip coating method for the polymer film deposition depends largely on the ability to achieve high polymer concentration in solutions. Another important factor is the molecular weight of a polymer. The use of a high molecular weight polymer is critically important for the film deposition. However, the polymer solubility in a solvent usually decreases with increasing molecular mass of polymer macromolecules due to enhanced interactions of long polymer chains. Ethanol is known as a non-solvent for PEMA. Despite the insolubility of PEMA in ethanol solvent, we dissolved PEMA in ethanol in the presence of LA as a solubilizing agent. Therefore, the use of toxic and carcinogenic solvents for PEMA deposition can be avoided. Moreover, we achieved solutions of relatively high concentrations using high molecular mass PEMA, which was a key factor of film deposition by a dip-coating method. The use of LA was motivated by the analysis of literature $[34,35]$ on solubilization of different biomolecules in a human body by bile salts. The remarkable solubilization power of bile salts in water are related to their electric charge and amphiphilic structure. It should be noted that in contrast to bile salts, which are highly soluble in water, LA and other bile acids are water insoluble. Bile salts solubilize small lipid molecules, such as cholesterol and fatty acids in water. In contrast we solubilized large PEMA polymer macromolecules in ethanol using LA.

The dissolution of polymers in pure solvents usually involves solvent diffusion and polymer chain disentanglement [36]. It is suggested that small LA molecules in ethanol penetrated between PEMA chains and adsorbed on PEMA. The adsorption mechanism involved hydrophobic interactions of PEMA and LA. The increase in the solvent temperature to $35^{\circ} \mathrm{C}$ facilitated LA diffusion. The adsorbed charged LA molecules provided electrostatic repulsion of the PEMA chains and promoted dissolution. After cooling down to room temperature, LA remained adsorbed on PEMA chains and allowed for the fabrication of stable solutions for the dip coating (Supplementary information, Figure S1).

Figure 2A shows an SEM image of a PEMA film. It contains a relatively dense bottom layer and a porous fibrous network on the surface. Annealing resulted in the formation of dense smooth films (Figure 2B). The morphological changes in the films during annealing can be attributed to the enhanced mobility of the polymer macromolecules with increased temperature, which can result in the merging of individual particles, reduction or 
elimination of porosity and formation of dense films [37,38]. The formation of dense films after annealing was critical for their corrosion protection ability. The dense layer acted as a physical barrier, thus preventing electrolyte contact with the stainless-steel substrate. The corrosion protection abilities were verified by potentiodynamic polarization studies in a $3 \%$ $\mathrm{NaCl}$ solution (Figure 3).
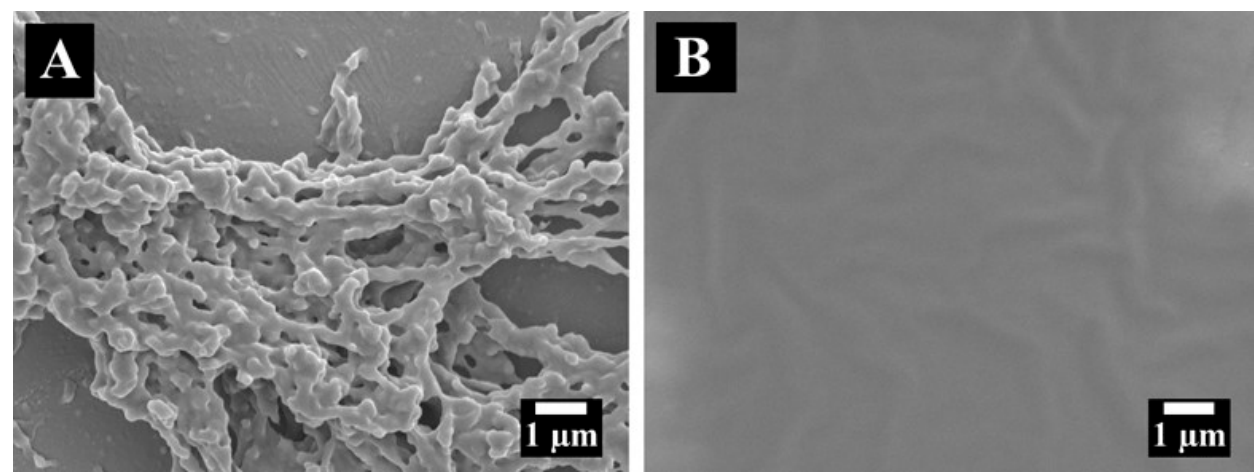

Figure 2. SEM micrographs for a film, prepared from $10 \mathrm{gL}^{-1}$ PEMA with $1 \mathrm{gL}^{-1} \mathrm{LA}$ solution: (A) as-deposited and (B) after annealing at $180^{\circ} \mathrm{C}$ for one hour.

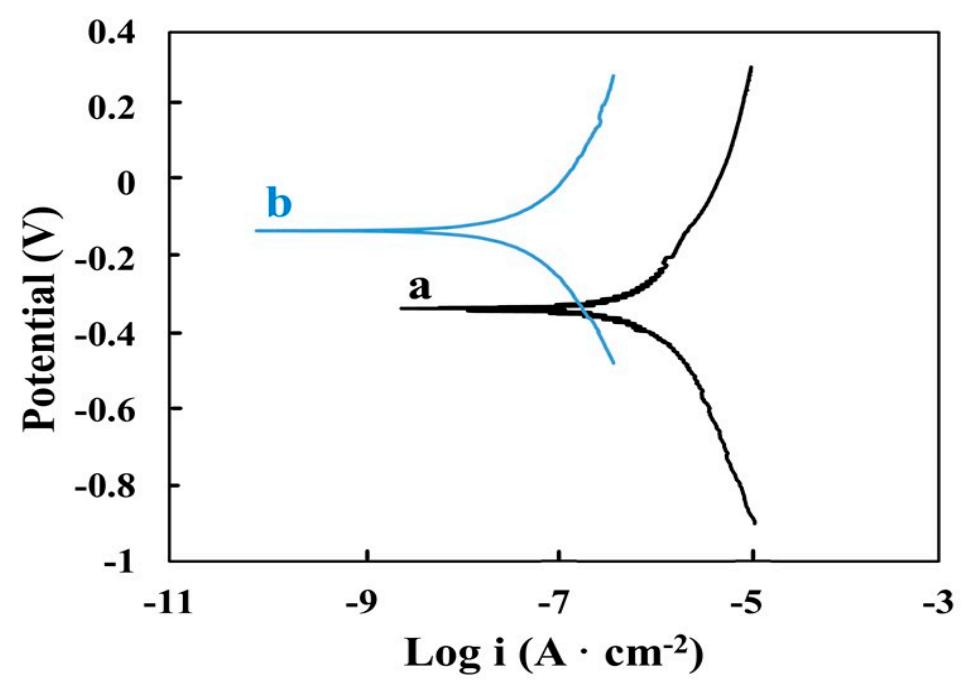

Figure 3. Tafel plots for (a) uncoated and (b) coated stainless steel sample prepared from a $10 \mathrm{gL}^{-1}$ PEMA solution containing $1 \mathrm{gL}^{-1} \mathrm{LA}$ in ethanol and annealed at $180^{\circ} \mathrm{C}$ for one hour.

The generated Tafel plot (Figure 3) compares the uncoated stainless-steel substrate to the substrate containing the annealed PEMA film. A substantial increase in corrosion potential can be observed for the coated sample relative to the bare substrate, as well as a decrease in anodic current, indicating increased corrosion resistance. In addition to the use of non-toxic and biocompatible solvents and solubilizing agents, the corrosion protection ability of the fabricated film further enhances their potential use in biomedical applications.

The addition of inorganic bioactive materials, such as hydroxyapatite and silica, to polymer films is widely used for the surface modification of biomedical implants $[39,40]$. These two materials have specific advantageous properties for orthopaedic applications. Hydroxyapatite is notably bioactive. Nanostructured hydroxyapatite makes up 70\% of natural bone, thus its presence in coatings can contribute to promoting new bone growth.

Silica is biocompatible and its presence in coatings for biomedical applications can help to inhibit inflammatory responses. It can also aid in the formation of new bone material, such as hydroxyapatite [41].

Composite PEMA-hydroxyapatite and PEMA-silica films were prepared by a dip coating method (Supplementary information, Figure S1). In this approach, LA acted as a 
solubilizing agent for PEMA and a dispersant for the ceramic particles, which facilitated the fabrication of stable suspensions of the particles in the PEMA solutions. Figure 4 shows SEM images for PEMA-hydroxyapatite films.
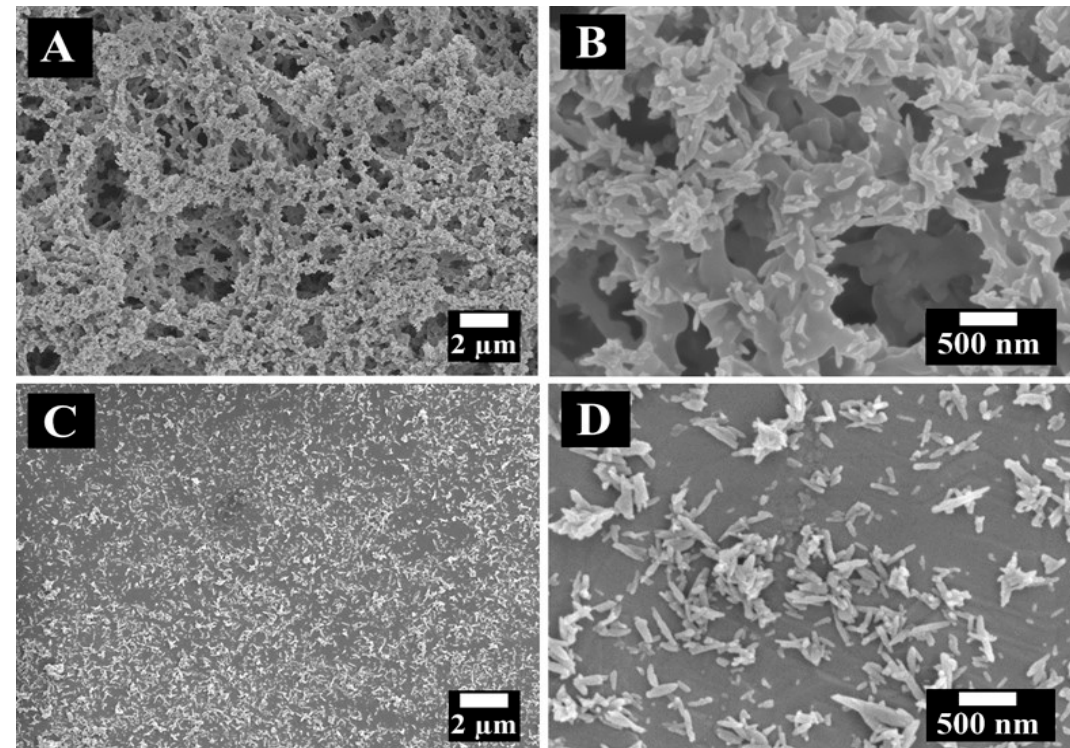

Figure 4. SEM micrographs at different magnifications for films prepared from $10 \mathrm{gL}^{-1} \mathrm{PEMA}$ solutions in ethanol, containing $3 \mathrm{gL}^{-1} \mathrm{LA}$ and $3 \mathrm{gL}^{-1}$ hydroxyapatite: $(\mathbf{A}, \mathbf{B})$ as deposited $(\mathbf{C}, \mathbf{D})$ annealed at $180{ }^{\circ} \mathrm{C}$ for one hour.

The SEM images for as-deposited films showed a porous microstructure; film annealing resulted in the formation of dense layers. High magnification images showed non-agglomerated hydroxyapatite nanorods in the PEMA matrix. Figure 5 shows SEM images of PEMA-silica films.
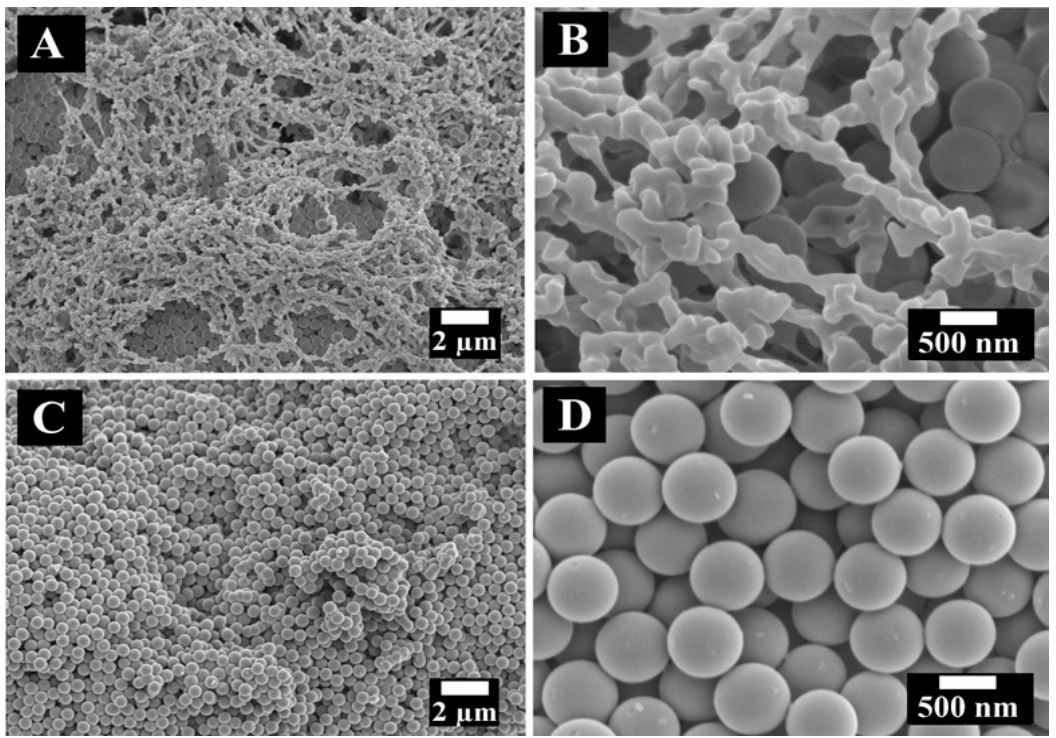

Figure 5. SEM micrographs at different magnifications for films prepared from $10 \mathrm{gL}^{-1} \mathrm{PEMA}$ solutions in ethanol, containing $3 \mathrm{gL}^{-1} \mathrm{LA}$ and $3 \mathrm{gL}^{-1}$ silica: $(\mathbf{A}, \mathbf{B})$ as deposited $(\mathbf{C}, \mathbf{D})$ annealed at $180^{\circ} \mathrm{C}$ for one hour.

The SEM images of as-deposited PEMA-silica films show a porous microstructure. Annealed films showed spherical silica particles in the PEMA matrix. The silica particles were relatively densely packed and PEMA was distributed between the particles. 
Concentrations of the bioceramics were able to be increased from 3 up to $10 \mathrm{gL}^{-1}$ due to the excellent dispersing ability of LA. In order to quantifiably confirm the increased amount of inorganics within the films, TGA studies were carried out (Figure 6). The PEMA-hydroxyapatite and PEMA-silica deposits were analysed by TGA. Figure 6 shows TGA data for films prepared from suspensions with different concentrations of ceramic particles. The observed mass loss was related to the burning out of PEMA and LA. The total mass loss for PEMA-hydroxyapatite films prepared from $10 \mathrm{gL}^{-1}$ PEMA solutions with $3 \mathrm{gL}^{-1} \mathrm{LA}$, containing $3 \mathrm{gL}^{-1}$ and $10 \mathrm{gL}^{-1}$ hydroxyapatite was found to be $82.4 \%$ and $56.4 \%$, which corresponded to hydroxyapatite content in the composite films of $17.6 \%$, and $43.6 \%$, respectively. The total mass loss for PEMA-silica films prepared from $10 \mathrm{gL}^{-1}$ PEMA solutions with $3 \mathrm{gL}^{-1} \mathrm{LA}$, containing $3 \mathrm{gL}^{-1}$ and $10 \mathrm{gL}^{-1}$ silica was found to be $74.2 \%$ and $50.3 \%$, which corresponded to silica content in the composite films of $25.8 \%$, and $49.7 \%$, respectively. TGA testing results indicated that hydroxyapatite and silica content in the composite films increased with increasing particle concentration in the suspensions and the film composition can be varied.

A

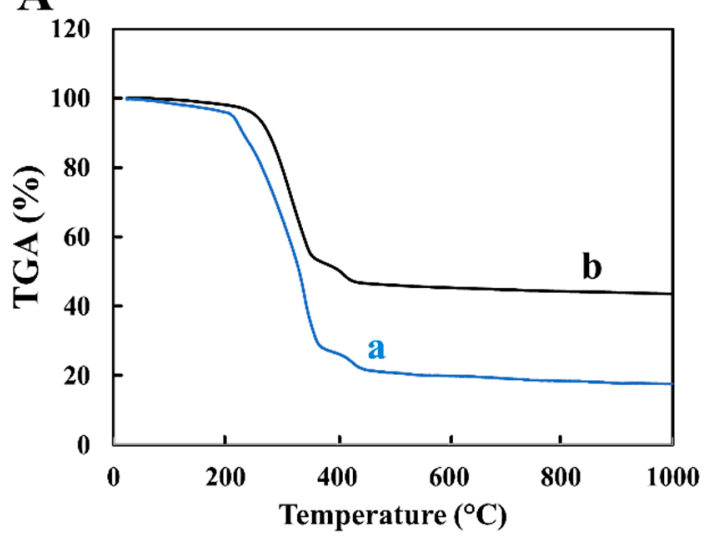

B

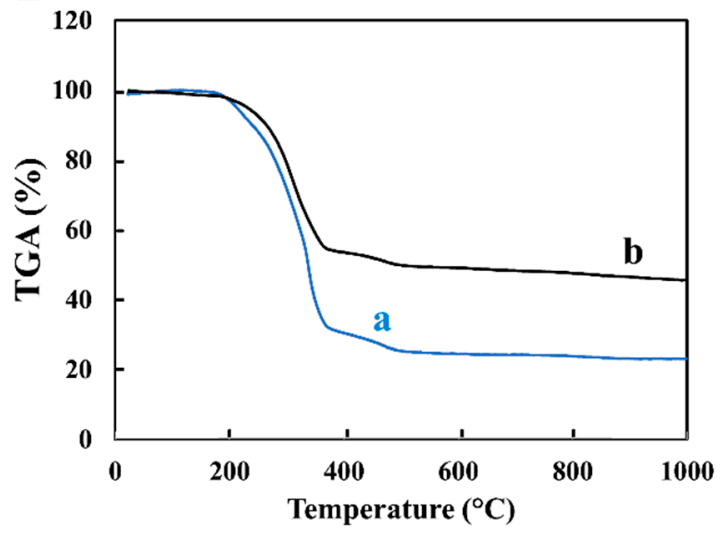

Figure 6. TGA data for composites prepared from $10 \mathrm{gL}^{-1}$ PEMA and $3 \mathrm{gL}^{-1}$ LA solutions in ethanol, containing (A) (a) 3, (b) $10 \mathrm{gL}^{-1}$ hydroxyapatites, and (B) (a) 3 and (b) $10 \mathrm{gL}^{-1}$ silica.

In this work composite films were obtained from PEMA solutions in ethanol that also contained other biologically functional materials. These materials included drugs such as the antibiotic tetracycline and anti-inflammatory ibuprofen, as well as the quickly emerging biomaterial nanocellulose. In this investigation, ibuprofen and tetracycline were used as model drugs for the fabrication of composite films. The analysis of SEM images of as-deposited films at different magnification indicated that such films were porous (Figure 7). The SEM images of as-deposited PEMA-nanocellulose films showed a similar microstructure (Figure 8). The composite coatings were studied by XRD and FTIR methods.

In the FTIR spectra of all the starting materials (Figure 9A), important characteristic peaks are labelled, and then seen again in the FTIR spectra from deposits of the composite coatings (Figure 9B). Ibuprofen's FTIR spectrum has peaks at 779, 933, 1230, 1420 and $1706 \mathrm{~cm}^{-1}$ due to $\mathrm{CH}_{2}$ rocking, $\mathrm{CH}_{3}$ rocking, $\mathrm{C}-\mathrm{C}$ stretching, and $\mathrm{CH}-\mathrm{CO}$ deformation and $\mathrm{C}=\mathrm{O}$ stretching, respectively [42]. The spectrum of tetracycline has peaks at 1024, 1143, $1236 \mathrm{~cm}^{-1}$ related to $\mathrm{C}-\mathrm{H}$ in plane deformation and $1448 \mathrm{~cm}^{-1}$ due to C-H bending [43]. The spectrum of nanocellulose showed absorptions at 1053, 1107 and $1161 \mathrm{~cm}^{-1}$, attributed to the C-O-C pyranose ring vibrations $[44,45]$. The FTIR spectrum of pure PEMA shows absorptions at 1022, 1140 and $1720 \mathrm{~cm}^{-1}$ related to $\mathrm{C}-\mathrm{H}$ bending, $\mathrm{C}-\mathrm{O}-\mathrm{C}$ symmetric stretching and $\mathrm{C}=\mathrm{O}$ stretching, respectively $[46,47]$. The deposited material of all three composite films contained peaks characteristic of PEMA and the specific added functional materials. 

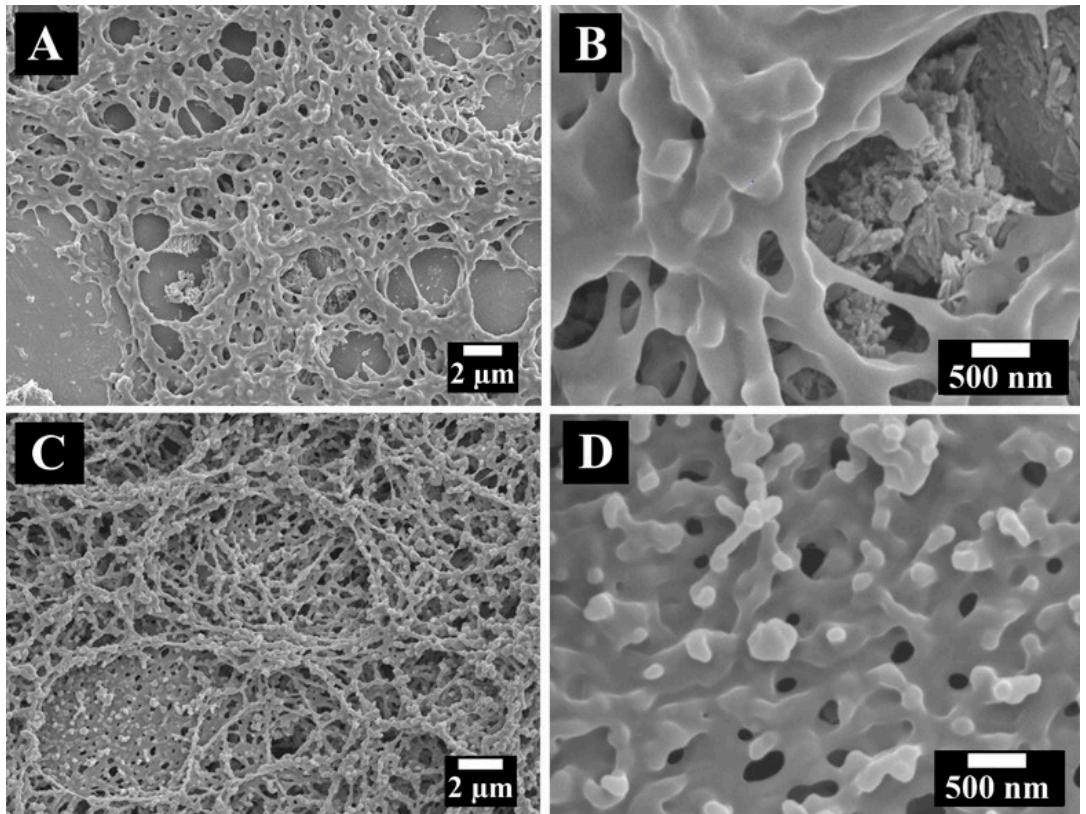

Figure 7. SEM micrographs of films at different magnifications for $10 \mathrm{gL}^{-1}$ PEMA solutions, with $3 \mathrm{gL}^{-1} \mathrm{LA}$ and containing (A,B) $3 \mathrm{gL}^{-1}$ ibuprofen and (C,D) $3 \mathrm{gL}^{-1}$ tetracycline.
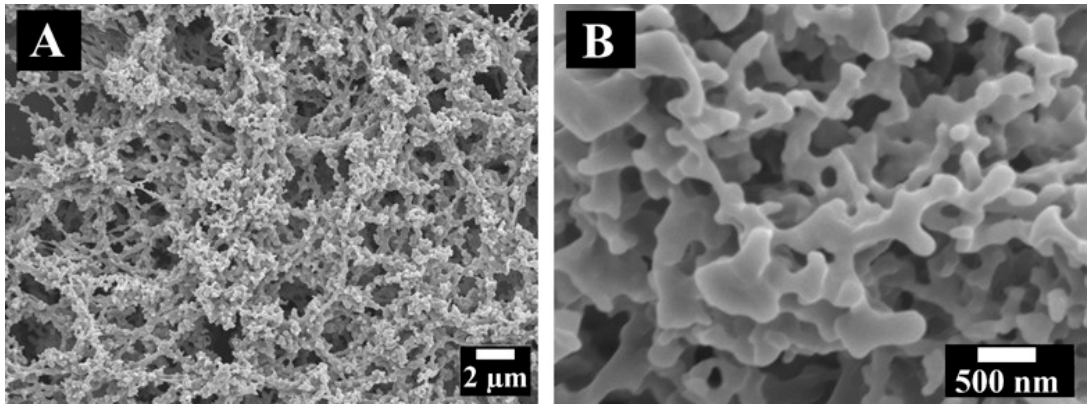

Figure 8. SEM micrographs at different magnifications of films, prepared from $10 \mathrm{gL}^{-1} \mathrm{PEMA}$ with $3 \mathrm{gL}^{-1} \mathrm{LA}$ and $3 \mathrm{gL}^{-1}$ nanocellulose. ((A) $\left.5000 \times\right),((\mathbf{B}) 30,000 \times)$.
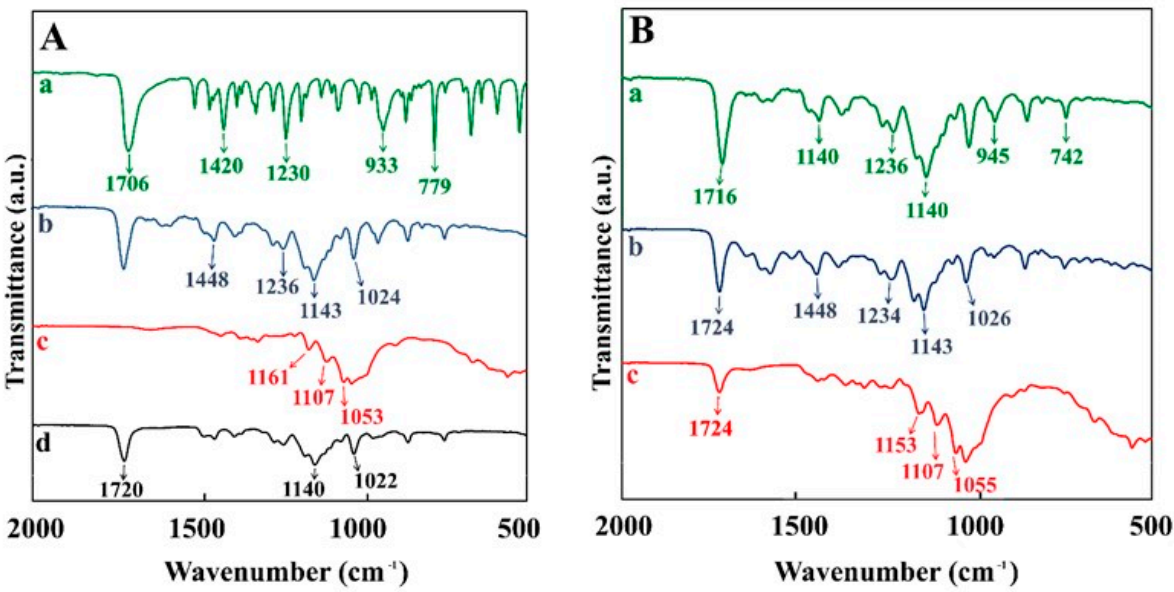

Figure 9. FTIR spectra of (A) pure materials: (a) ibuprofen, (b) tetracycline, (c) nanocellulose, and (d) PEMA. (B) composite films: (a) PEMA-ibuprofen, (b) PEMA-tetracycline and (c) PEMA-nanocellulose.

In addition to FTIR characterization, XRD was also used to analyse the composite coatings. The X-ray diffraction patterns for starting materials are shown in Figure 10A. PEMA showed very broad peaks in the range of $10-20^{\circ}$. Nanocellulose, tetracycline, 
and ibuprofen showed peaks corresponding to their JCPDS files 058-1718, 039-1985, and 0032-1723, respectively. The X-ray diffraction patterns of composite films are presented in Figure 10B. Composite PEMA-ibuprofen films showed peaks of ibuprofen combined with broad peaks of PEMA. The deposition of tetracycline with PEMA in ethanol led to its amorphization, but the most dominant peaks were still slightly visible. The X-ray diffraction pattern of PEMA-nanocellulose films showed peaks of nanocellulose. It is suggested that broad peaks of PEMA overlapped with nanocellulose peaks and were not observed in the X-ray diffraction pattern of the composite. It is also known that polymer amorphization can be observed in composites under the influence of another polymer or additive [48-50].
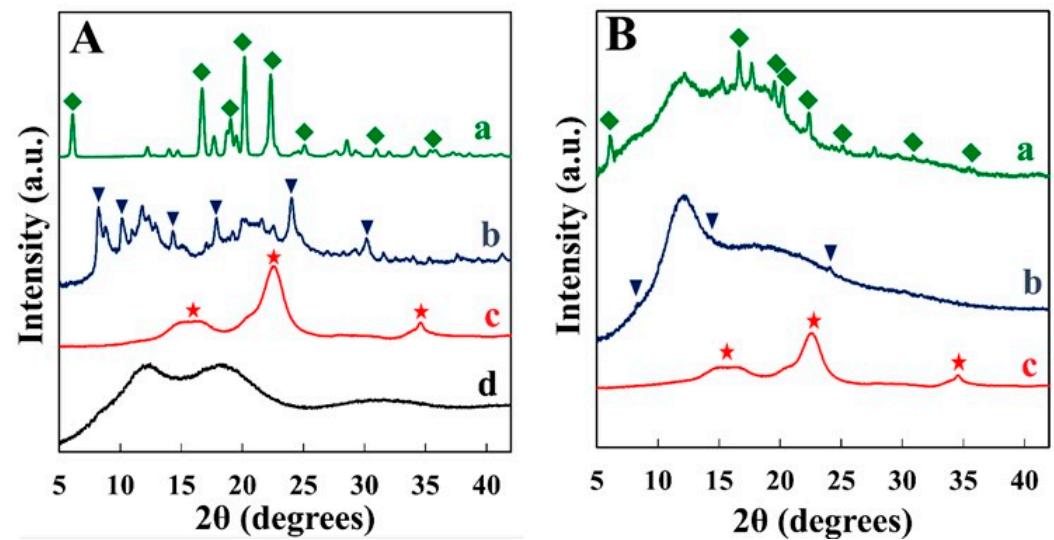

Figure 10. XRD patterns of (A) pure materials: (a) ibuprofen, (b) tetracycline, (c) nanocellulose, and (d) PEMA, (B) composite coatings: (a) PEMA-ibuprofen, (b) PEMA-tetracycline and (c) PEMA-

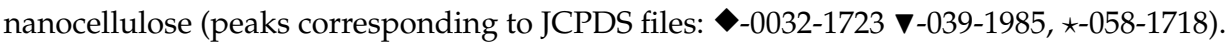

The XRD studies in addition to the FTIR spectra proved the co-deposition of PEMA with drugs and nanocellulose. The results of this investigation indicated that the dip coating methods presents a versatile strategy for the co-deposition of various functional materials for biomedical applications. Water droplet contact angle measurements showed that as-deposited PEMA films and composite films reduced surface wettability of the substrates (Supplementary information, Figures S2 and S3 and Table S1). We found that the dip coating method can be used for the fabrication of multilayer films, containing individual layers with different functionalities.

\section{Conclusions}

This study showed that PEMA can be dissolved in ethanol in the presence of LA. The ability to avoid the use of toxic solvents for PEMA opens an avenue for the fabrication of composite films for biomedical and other applications. Of particular importance is the use of a natural bile acid as a solubilizing agent for PEMA and as a dispersing agent for inorganic particles. The formation of concentrated solutions of high molecular mass PEMA was one of the key factors for the successful deposition of PEMA films by a dip-coating method. The annealed PEMA films provided corrosion protection for stainless steel. It was found that LA acted as a dispersant for the hydroxyapatite and silica and facilitated the fabrication of composite PEMA-hydroxyapatite and PEMA-silica films. The composition of the films can be varied and controlled by the variation in concentration of the inorganic particles in the suspensions. The dip coating method has been used for the fabrication of composite coatings, containing drugs and nanocellulose. Therefore, the proposed method represents a versatile platform for the fabrication of composite films, containing various functional materials. 
Supplementary Materials: The following supporting information can be downloaded at: https: / / www.mdpi.com/article/10.3390/jcs6020040/s1, Figure S1: Photographs of uncoated and coated substrates, Figures S2 and S3 and Table S1: Water droplet contact angle measurements data for uncoated and coated substrates.

Author Contributions: Conceptualization, K.B. and I.Z.; methodology, K.B.; validation, K.B. formal analysis, K.B.; investigation, K.B.; resources, I.Z.; data curation, K.B.; writing-original draft preparation, K.B. and I.Z.; writing-review and editing, K.B. and I.Z.; supervision, I.Z.; project administration, I.Z.; funding acquisition, I.Z. All authors have read and agreed to the published version of the manuscript.

Funding: This research was funded by the Natural Sciences and Engineering Research Council of Canada, grant number RGPIN-2018-04014 and CRC program.

Acknowledgments: The authors acknowledge the support of the Natural Sciences and Engineering Research Council (NSERC) of Canada, CRC program and of the Canadian Centre for Electron Microscopy.

Conflicts of Interest: The authors declare no conflict of interest.

\section{References}

1. Mohanty, F.; Swain, S.K. Effect of graphene platelets on the thermal and conducting properties of poly (ethyl methacrylate). Adv. Polym. Technol. 2018, 37, 1316-1322. [CrossRef]

2. Abdelrazek, E. Influence of $\mathrm{FeCl}_{3}$ filler on the structure and physical properties of polyethyl-methacrylate films. Phys. B Condens. Matter 2007, 400, 26-32. [CrossRef]

3. Armstrong, R.; Wright, J. Impedance studies of poly ethylmethacrylate coatings formed upon tin-free steel. Corros. Sci. 1992, 33, 1529-1539. [CrossRef]

4. Mohanty, F.; Swain, S.K. Silver Nanoparticles Decorated Polyethylmethacrylate/Graphene Oxide Composite: As Packaging Material. Polym. Compos. 2019, 40, E1199-E1207. [CrossRef]

5. Mohanty, F.; Swain, S.K. Nano silver embedded starch hybrid graphene oxide sandwiched poly (ethylmethacrylate) for packaging application. Nano-Struct. Nano-Objects 2019, 18, 100300. [CrossRef]

6. Li, J.; Tan, S.; Ding, S.; Li, H.; Yang, L.; Zhang, Z. High-field antiferroelectric behaviour and minimized energy loss in poly (vinylidene-co-trifluoroethylene)-graft-poly (ethyl methacrylate) for energy storage application. J. Mater. Chem. 2012, 22, 23468-23476. [CrossRef]

7. Ulaganathan, M.; Mathew, C.M.; Rajendran, S. Highly porous lithium-ion conducting solvent-free poly (vinylidene fluoride-cohexafluoropropylene)/poly (ethyl methacrylate) based polymer blend electrolytes for Li battery applications. Electrochim. Acta 2013, 93, 230-235. [CrossRef]

8. Ramesh, S.; Uma, O.; Shanti, R.; Yi, L.J.; Ramesh, K. Preparation and characterization of poly (ethyl methacrylate) based polymer electrolytes doped with 1-butyl-3-methylimidazolium trifluoromethanesulfonate. Measurement 2014, 48, 263-273. [CrossRef]

9. Sari, A.; Karlı, A.; Alkan, C.; Karaipekli, A. Polyethyl methacrylate (PEMA)/fatty acids blends as novel phase change materials for thermal energy storage. Energy Sources Part A Recovery Util. Environ. Eff. 2013, 35, 1813-1819. [CrossRef]

10. Zakaria, N.; Isa, M.; Mohamed, N.; Subban, R. Characterization of polyvinyl chloride/polyethyl methacrylate polymer blend for use as polymer host in polymer electrolytes. J. Appl. Polym. Sci. 2012, 126, E419-E424. [CrossRef]

11. Arnold, J.C.; Venditti, N.P. Prediction of the long-term creep behaviour of hydroxyapatite-filled polyethylmethacrylate bone cements. J. Mater. Sci. Mater. Med. 2007, 18, 1849-1858. [CrossRef] [PubMed]

12. Dalby, M.; Di Silvio, L.; Harper, E.; Bonfield, W. In vitro adhesion and biocompatability of osteoblast-like cells to poly (methylmethacrylate) and poly (ethylmethacrylate) bone cements. J. Mater. Sci. Mater. Med. 2002, 13, 311-314. [CrossRef] [PubMed]

13. Kim, M.S.; Jun, J.K.; Jeong, H.M. Shape memory and physical properties of poly (ethyl methacrylate)/Na-MMT nanocomposites prepared by macroazoinitiator intercalated in Na-MMT. Compos. Sci. Technol. 2008, 68, 1919-1926. [CrossRef]

14. Barry, J.; Gidda, H.; Scotchford, C.; Howdle, S. Porous methacrylate scaffolds: Supercritical fluid fabrication and in vitro chondrocyte responses. Biomaterials 2004, 25, 3559-3568. [CrossRef]

15. Hutcheon, G.; Messiou, C.; Wyre, R.; Davies, M.; Downes, S. Water absorption and surface properties of novel poly (ethylmethacrylate) polymer systems for use in bone and cartilage repair. Biomaterials 2001, 22, 667-676. [CrossRef]

16. Barry, J.J.; Silva, M.M.; Cartmell, S.H.; Guldberg, R.E.; Scotchford, C.A.; Howdle, S.M. Porous methacrylate tissue engineering scaffolds: Using carbon dioxide to control porosity and interconnectivity. J. Mater. Sci. 2006, 41, 4197-4204. [CrossRef]

17. Özcan, M.; Hotza, D.; Fredel, M.C.; Cruz, A.; Volpato, C.A.M. Materials and Manufacturing Techniques for Polymeric and Ceramic Scaffolds Used in Implant Dentistry. J. Compos. Sci. 2021, 5, 78. [CrossRef]

18. Moura, N.K.; Siqueira, I.A.W.B.; Machado, J.P.B.; Kido, H.W.; Avanzi, I.R.; Rennó, A.C.M.; Trichês, E.S.; Passador, F.R. Production and Characterization of Porous Polymeric Membranes of PLA/PCL Blends with the Addition of Hydroxyapatite. J. Compos. Sci. 2019, 3, 45. [CrossRef] 
19. Grandfield, K.; Zhitomirsky, I. Electrophoretic deposition of composite hydroxyapatite-silica-chitosan coatings. Mater. Charact. 2008, 59, 61-67. [CrossRef]

20. Balla, E.D.; Bikiaris, N.D.; Nanaki, S.G.; Papoulia, C.; Chrissafis, K.; Klonos, P.A.; Kyritsis, A.; Kostoglou, M.; Zamboulis, A.; Papageorgiou, G.Z. Chloramphenicol Loaded Sponges Based on PVA/Nanocellulose Nanocomposites for Topical Wound Delivery. J. Compos. Sci. 2021, 5, 208. [CrossRef]

21. Mirtaghavi, A.; Luo, J.; Muthuraj, R. Recent Advances in Porous 3D Cellulose Aerogels for Tissue Engineering Applications: A Review. J. Compos. Sci. 2020, 4, 152. [CrossRef]

22. Anton-Sales, I.; Roig-Sanchez, S.; Traeger, K.; Weis, C.; Laromaine, A.; Turon, P.; Roig, A. In vivo soft tissue reinforcement with bacterial nanocellulose. Biomater. Sci. 2021, 9, 3040-3050. [CrossRef] [PubMed]

23. Echeverry-Rendon, M.; Reece, L.M.; Pastrana, F.; Arias, S.L.; Shetty, A.R.; Pavón, J.J.; Allain, J.P. Bacterial Nanocellulose Magnetically Functionalized for Neuro-Endovascular Treatment. Macromol. Biosci. 2017, 17, 1600382. [CrossRef] [PubMed]

24. Bharimalla, A.; Deshmukh, S.; Vigneshwaran, N.; Patil, P.; Prasad, V. Nanocellulose-polymer composites for applications in food packaging: Current status, future prospects and challenges. Polym.- Plast. Technol. Eng. 2017, 56, 805-823. [CrossRef]

25. Koppolu, R.; Lahti, J.; Abitbol, T.; Swerin, A.; Kuusipalo, J.; Toivakka, M. Continuous processing of nanocellulose and polylactic acid into multilayer barrier coatings. ACS Appl. Mater. Interfaces 2019, 11, 11920-11927. [CrossRef] [PubMed]

26. Wesling, B.N.; Dias, G.M.; Müller, D.; Serpa, R.B.; Hotza, D.; Rambo, C.R. Enhanced Electrochemical Performance of Nanocellulose/PPy. CuCl 2 Electrodes for All-Cellulose-Based Supercapacitors. J. Electron. Mater. 2020, 49, 1036-1042. [CrossRef]

27. Brett, C.J.; Ohm, W.; Fricke, B.R.; Alexakis, A.E.; Laarmann, T.; Körstgens, V.; Müller-Buschbaum, P.; Söderberg, L.D.; Roth, S.V. Nanocellulose-Assisted Thermally Induced Growth of Silver Nanoparticles for Optical Applications. ACS Appl. Mater. Interfaces 2021, 13, 27696-27704. [CrossRef]

28. Herrera, M.A.; Sirviö, J.A.; Mathew, A.P.; Oksman, K. Environmental friendly and sustainable gas barrier on porous materials: Nanocellulose coatings prepared using spin-and dip-coating. Mater. Des. 2016, 93, 19-25. [CrossRef]

29. Lang, A.W.; Österholm, A.M.; Reynolds, J.R. Paper-based electrochromic devices enabled by nanocellulose-coated substrates. Adv. Funct. Mater. 2019, 29, 1903487. [CrossRef]

30. Mazloum-Ardakani, M.; Arazi, R.; Mirjalili, B.B.F.; Azad, S. Synthesis and application of $\mathrm{Fe}_{3} \mathrm{O}_{4} @$ nanocellulose/TiCl as a nanofiller for high performance of quasisolid-based dye-sensitized solar cells. Int. J. Energy Res. 2019, 43, 4483-4494. [CrossRef]

31. Feldman, D. Poly(Vinyl Alcohol) Recent Contributions to Engineering and Medicine. J. Compos. Sci. 2020, 4, 175. [CrossRef]

32. Sikkema, R.; Baker, K.; Zhitomirsky, I. Electrophoretic deposition of polymers and proteins for biomedical applications. Adv. Colloid Interface Sci. 2020, 284, 102272. [CrossRef] [PubMed]

33. Deen, I.; Pang, X.; Zhitomirsky, I. Electrophoretic deposition of composite chitosan-halloysite nanotube-hydroxyapatite films. Colloids Surf. A Physicochem. Eng. Asp. 2012, 410, 38-44. [CrossRef]

34. Baker, K.; Sikkema, R.; Liang, W.; Zhitomirsky, I. Multifunctional Properties of Commercial Bile Salts for Advanced Materials Engineering. Adv. Eng. Mater. 2021, 23, 2001261. [CrossRef]

35. Baker, K.; Sikkema, R.; Zhitomirsky, I. Application of bile acids for biomedical devices and sensors. Med. Devices Sens. 2020, 3, e10119. [CrossRef]

36. Miller-Chou, B.A.; Koenig, J.L. A review of polymer dissolution. Prog. Polym. Sci. 2003, 28, 1223-1270. [CrossRef]

37. Aburideh, H.; Merzouk, N.K.; Naceur, M.W.; Tigrine, Z.; Tassalit, D.; Abbas, M. Thermal annealing effect on morphology and performance of polysulfone-cellulose acetate membranes: Application for water defluoridation technology. Cellul. Chem. Technol. 2019, 53, 583-597. [CrossRef]

38. Zidan, T.; El-Menyawy, E. Thermal annealing-induced enhanced ordering and optical functions modification on poly (3octylthiophene) films. Polym. Test. 2019, 75, 270-276. [CrossRef]

39. Sikkema, R.; Keohan, B.; Zhitomirsky, I. Alginic Acid Polymer-Hydroxyapatite Composites for Bone Tissue Engineering. Polymers 2021, 13, 3070. [CrossRef]

40. Sikkema, R.; Keohan, B.; Zhitomirsky, I. Hyaluronic-Acid-Based Organic-Inorganic Composites for Biomedical Applications. Materials 2021, 14, 4982. [CrossRef]

41. Huang, Y.; Wu, C.; Zhang, X.; Chang, J.; Dai, K. Regulation of immune response by bioactive ions released from silicate bioceramics for bone regeneration. Acta Biomater. 2018, 66, 81-92. [CrossRef] [PubMed]

42. Acharya, M.; Mishra, S.; Sahoo, R.N.; Mallick, S. Infrared spectroscopy for analysis of co-processed ibuprofen and magnesium trisilicate at milling and freeze drying. Acta Chim. Slov. 2017, 64, 45-54. [CrossRef]

43. Trivedi, M.K.; Patil, S.; Shettigar, H.; Bairwa, K.; Jana, S. Spectroscopic characterization of chloramphenicol and tetracycline: An impact of biofield treatment. Pharm. Anal. Acta 2015, 6, 395.

44. Mandal, A.; Chakrabarty, D. Isolation of nanocellulose from waste sugarcane bagasse (SCB) and its characterization. Carbohydr. Polym. 2011, 86, 1291-1299. [CrossRef]

45. Morán, J.I.; Alvarez, V.A.; Cyras, V.P.; Vázquez, A. Extraction of cellulose and preparation of nanocellulose from sisal fibers. Cellulose 2008, 15, 149-159. [CrossRef]

46. Li, X.; Zhitomirsky, I. Deposition of poly (methyl methacrylate) and composites containing bioceramics and bioglass by dip coating using isopropanol-water co-solvent. Prog. Org. Coat. 2020, 148, 105883. [CrossRef]

47. Jankovic, I.A.; Saponjic, Z.V.; Comor, M.I.; Nedeljkovic, J.M. Surface modification of colloidal TiO ${ }_{2}$ nanoparticles with bidentate benzene derivatives. J. Phys. Chem. C 2009, 113, 12645-12652. [CrossRef] 
48. Thitisomboon, W.; Gu, Q.; Weng, L.-T.; Gao, P. Surface confinement induced amorphization of polyethylene oxide in highperformance porous polyethylene films. Polymer 2021, 217, 123449. [CrossRef]

49. Trifol, J.; Van Drongelen, M.; Clegg, F.; Plackett, D.; Szabo, P.; Daugaard, A. Impact of thermal processing or solvent casting upon crystallization of PLA nanocellulose and/or nanoclay composites. J. Appl. Polym. Sci. 2019, 136, 47486. [CrossRef]

50. Mileva, D.; Tranchida, D.; Gahleitner, M. Designing polymer crystallinity: An industrial perspective. Polym. Cryst. 2018, 1, e10009. [CrossRef] 